tate of ammonia, half an ounce; tincture of the sesquichloride of iron, twenty minims : three times a day. ${ }^{*}$ The whole surface of the body and limbs to be sponged with glycerine and water in equal parts night and morning. The effect of the glycerine was soon developed in a free and gentle perspiration. The dropsy began rapidly to subside, the amount of albumen in the urine to diminish. The skin now feels natural, and performs its functions actively. It is probable that glycerine has a twofold action on the skin, both tending to the same endIst, it softens the cuticle, and removes obstructions from the orifices of the sweat-ducts ; 2 ndly, it possibly acts by inducing the escape of fluid by exosmosis. I have used it in several cases of acute dropsy with albuminuria after scarlatina, with good results. I have not found it to produce any injurious effects in any case.

Woburn-place, December, 1861.

\section{DISLOCATION OF THE ASTRAGALUS OUTWARDS.}

\section{Bx EDWARD CROOKE, M.D. EDIN.}

J. A-, a thin, spare man, aged forty-five, whilst cleaning $a$ window about fourteen feet from the ground, on the loth of October, fell from the ladder on which he was standing. I saw him about one hour afterwards, and found him in a very prostrate condition, complaining of intense pain in his left foot and ankle. Upon examination, the foot was seen in a very exag. gerated position of talipes varus. Externally was a hard swel. ling, over which the integuments were very tightly stretched. The swelling was easily distinguished to be the displaced astragalus, with the superior surface looking outwards, the inferior inwards, the internal upwards, the external downwards, the anterior and posterior maintaining their usual aspects in a semiinverted position. The manner in which the foot came in contact with the ground could not be described. Contrary to my expectation, (on account of the nature of the injury,) reduction was easily effected by flexing the leg, and the use of moderate extension, pressure being at the same time applied to the bone in an upward and inward direction. At the end of seven weeks the man returned to his work.

Chorley, Lancashire, Dec. 1861.

\section{a ditrutor}

\section{OF THE PRACTICE OF}

\section{MEDICINE AND SURGERT IN THE}

\section{HOSPITALS OF LONDON.}

Nulla est alia pro certo noscendi via, nisi quam plurimas et morborum et dissectionum historias, tam aliorum proprias, collectas habere et inter se comparare.-Morgagni. De Sed. et Caus. Morb., lib, 14. Procmium.

\section{UNIVERSITY COLLEGE HOSPITAL.}

DIFFUSED FEMORAL ANEURISM, THE RESULT OF SPONTANEOUS RUPTURE FROM DISEASE; DELIGATION OF THE EXTERNAL ILIAC; DeATH FROM PELVIC ABSCESS.

\section{(Under the care of Mr. Erichsen.)}

IT will be remarked that the patient in the following case was in comparatively good health some eight days before his admission into the hospital, when, after a fatiguing walk of five miles, he noticed a swelling in his thigh. This was the result of spontaneous rupture of the femoral artery at a part affected with calcareous disease, with the formation of a diffased aneurism.

On examination, the true nature of the malady was at once apparent ${ }_{3}$ for, besides the other symptoms present, when the

* I have used the tincture of the sesquichloride of iron in the most acute forms of dropsy with albuminuria from the earliest period of its accession, and the almost invariable effect has been a diminution in the amount of albumen, and an increase in the quantity of the urine. swelling was grasped with both hands the distensile pulsation was so strong as to separate them. Mr. Erichsen therefore had recourse to immediate operative measures, and placed a ligature upon the external iliac artery. The great effusion of blood over the common femoral, and the probability of its being much diseased, wholly precluded any interference with that vessel. The patient progressed very favourably for some days, but afterwards became low and feeble, although suffering no pain, and died on the thirty-sixth day, the fatal result being mainly brought about by intra-pelvic abscess, situated especially between the rectum and bladder, and unsuspected during life.

The following notes were kindly furnished by Mr. R. T. Warn, the dresser of the patient.

Samuel H___, sawyer, aged sixty.four years, married; has always had good health; lived regularly and well; has been a sober man; was admitted August 7 th, 1861 . On the 30th of July, he walked abont five miles, and came home very tired, but does not recollect to have had any blow or sudden strain on his leg. He then first noticed a lump on his thigh, about as large as a hen's egg. This appeared to him to pulsate, and he poulticed it. It gradually increased in size, and then, on the 3rd of August, some discoloration of ecchymosis came on the thigh above the swelling. He saw a medical man, wha sent him to this hospital. On admission, a lorge tumour was observed on the front of the right thigh, about the junction of the middle with the upper third. This was tense and shining, and of the natural colour of the skin; it had a distinct eccentric impulse; on listening with a stethoscope, the aneurismal bruit could be heard. Above the tumour considerable ecchymosis and fulness were observed, not reaching above Poupart's ligament, and chiefly on the inner side of the thigh. The limb was cold, but not œedematous. The patient was faint, his pulse weak, and he had an arcus senilis on both cornex. Mr. Erichsen saw the patient at two P. M., and decided on tying the external iliac, which he did by a semilunar incision just above Poupart's ligament. One small bleeding point required ligature. The artery at the point deligated-viz., just above the epigastricappeared to be quite healthy. The wound was brought together by a couple of points of suture, and the right limb ordered to be wrapped in a dry flannel, and kept in an elevated. position.

Aug. 8th.-Fleven A.M., twenty hours after the operation: Feels very comfortable; no pulsation in tumour; temperature of right foot $84^{\circ}$, of left, $83^{\circ}$; rather faint. Ordered beef-tea and brandy. - Five P. M.: Going on well; temperature of limb good; no pain.

9th.-Ten A.M.: Temperature half-way up right leg, $90^{\circ}$; between the toes of the same, $83^{\circ}$; sound leg, $94^{\circ}$. Slept pretty well last night; ecchymosis less; tumour less pro. minent.

10th.--Temperature between right toes, $86^{\circ}$; half-way up the leg, $95 \frac{1}{2}^{\circ}$. No pulsation in posterior tibial artery; very little venous congestion; tumour diminishing; passed a comfortable night; wound looking well, and suppurating kindly.

12th. - Patient feels pretty comfortable; appetite good; tongue clean; surface of limb covered with enlarged veins, and looks congested, not swollen or odematous; good motion and sensation. Temperature of right foot, $88^{\circ}$; half-way up leg, $93^{\circ}$; left leg, $96^{\circ}$. Wound healthy; sutures removed; discharges freely.

13th.-Bowels open twice to-day (first time since operation); expresses himself as much better; wound looking healthy, and suppurating kindly; no pain. Temperature between right toes, $88^{\circ}$; right leg, $95^{\circ}$; left toes, $80^{\circ}$.

14th. - Tongue pretty clean; bowels open yesterday; swelling much diminished, and ecchymosis also less; wound healthy, and suppurating kindly. Temperature of right leg, $95^{\circ}$; toes, $85^{\circ}$; left leg, $88^{\circ}$; toes, $80^{\circ}$. Some venous congestion on surface, but not more than on other leg; posterior tibial artery not to be felt; appetite good; slept well last night; altogether better since the operation.

20th. - Patient improving; wound healing fast; ligature not come away; tumour slightly increased in size since last note; temperature of both limbs the same.

24th. - Tumour a little larger, fluctuating under the finger; otherwise the patient is going on well. Ligature not come away; no rigors. Ordered the whole limb, including the tumour, to be enveloped in an elastic web bandage.

30th. - Tumour very little larger; appetite not good. Ordered one ounce of quinine mixture three times a day. Some soreness of the back ; to have applied to it collodion and castor oil in equal parts.

Sept. 2nd.-Tumour seems to be diminishing in size; appetite improved; ligature not yet come away. The patient is 